\title{
Influence of 5-fluorouracil on ferredoxin reductase mRNA splice variants in colorectal carcinomas
}

\author{
MARK SCHNEIDER ${ }^{1,3}$, MOTOKO TANAKA-NOZAKI ${ }^{2}$, SHUNJI KATO $^{2}$ and BRUNHILDE BLÖMEKE ${ }^{1,3}$ \\ ${ }^{1}$ Department of Environmental Toxicology, University of Trier, 54296 Trier, Germany; \\ ${ }^{2}$ Department of Surgery I, Nippon Medical School, Tokyo 113-8603, Japan
}

Received July 8, 2009; Accepted September 4, 2009

DOI: $10.3892 /$ ol_00000062

\begin{abstract}
Fluorouracil (5-FU) is a frequently used antitumor drug. Recently, it has been shown that mRNA and protein levels of the ferredoxin reductase gene (gene, FDXR; protein, FR) increase drastically after 5-FU treatment in various cell lines including colorectal cancer. The induction is mediated by p53 and enhanced reactive oxygen species (ROS)-associated apoptosis. Thus, knowledge about FDXR expression in human tissue and expression of the known splice variants is critical for understanding this finding. A sensitive and specific reverse transcriptase polymerase chain reaction (RT-PCR) assay for quantification of FDXR mRNA levels including the splice variants, a biological active variant (-18 bp) and an inactive variant (+18 bp), was developed and used to measure mRNAs after 5 -FU chemotherapy in colorectal tissues of 40 cancer patients prior to and after treatment with 5-FU for 14 days. Before treatment, the great majority of normal tissues expressed the splice variants in a 100:1 ratio in favor of the -18-variant similar to what has been reported for other tissues. In tumors, the mRNA levels of total FDXR and splice variants were approximately 2-fold higher compared to the normal tissue. After 5-FU treatment, levels of the +18 -variant increased 17 -fold in tumors and 31 -fold in normal tissues, clearly shifting the ratio towards the +18 -form. 5-FU-mediated -18-variant induction $(>1)$ in normal $(12 / 17)$ and tumor tissues (12/16) was apparently associated with response, while a balanced ratio (0.1-2) was associated
\end{abstract}

Correspondence to: Dr Brunhilde Blömeke, Department of Environmental Toxicology, University of Trier, Wissenschaftspark 25-27, 54296 Trier, Germany

E-mail: bloemeke@uni-trier.de

Present address: ${ }^{3}$ Department of Surgery, University Hospital of the RWTH Aachen, 52074 Aachen, Germany

Abbreviations: RT, reverse transcriptase; PCR, polymerase chain reaction; q-RT-PCR, quantitative reverse transcriptase polymerase chain reaction; 5-FU, 5-fluorouracil; FDXR, ferredoxin reductase gene; FR, ferredoxin reductase protein; ROS, reactive oxygen species; 5'DFUR, 5-FU prodrug doxifluridine

Key words: ferredoxin reductase, ferredoxin reductase splice variants, 5-fluorouracil, colorectal cancer, treatment success with 5-FU resistance $(n=5)$ based on the histological evaluation of the tissues.

\section{Introduction}

5-Fluorouracil (5-FU), a potent antitumor drug (1), is used for treatment of tumors such as colorectal (2), breast (3) and liver carcinomas (4). The main cytotoxic effects are likely to be mediated by the inhibition of thymidylate synthetase, a key enzyme that promotes the de novo synthesis of thymidylic acid, which leads to the formation of desoxythymidine triphosphate (dTTP) (5). Furthermore, 5-FU influences the processing of mRNA, rRNA and the interaction of t-RNA with the DNA primase (6). More recent studies have revealed another p53-dependent mechanism of 5-FU action. 5-FU treatment enhances expression of the ferredoxin reductase gene and protein, and this contributes to oxidative stress-mediated apoptosis $(7,8)$.

Ferredoxin reductase (protein, FR; gene, FDXR) is part of an electron transport system and is involved in the synthesis of steroid hormones by mitochondrial cytochrome P450scc. Here, FR catalyzes the rate limiting step namely the conversion of cholesterol to pregnenolone. The required electrons $(9,10)$ are transferred from NADPH to the flavoprotein ferredoxin reductase and the iron-sulfur protein adrenodoxin which mediates the electron transport to all mitochondrial forms of cytochrome P450 (11,12). Further studies indicate that the mitochondrial P450 systems can leak electrons and produce $\mathrm{O}_{2}$-derived free radicals. Reactive oxygen species (ROS), such as $\mathrm{H}_{2} \mathrm{O}_{2}$ or superoxide radicals, are known to be harmful to cells by damaging nucleic acids and proteins (13). Several groups have proposed that a feed forward loop beginning with 5-FU causes ROS-mediated cell damage and the stabilization of p53 as a mechanism for apoptosis. Subsequently, p53 induces expression of the FDXR mRNA and formation of ferredoxin reductase (FR), which sensitizes cells to ROS-mediated apoptosis (7). It was found that FDXR can be up-regulated by a p53 mutant that is competent in inducing apoptosis, but not by a tumor-derived p53 mutant that is defective in transactivation, which suggests that FDXR is a potential mediator of p53dependent apoptosis (8).

These studies clearly emphasize that, in addition to the biosynthesis of steroid hormones, FR sensitizes cancer cells to ROS-induced apoptosis. Two variants of the FDXR mRNA 
are known. The difference is based on a 18-bp deletion, which arises from a passive non-regulated alternative splicing at the 5 '-end of exon 7 (9). This region is directly adjacent to the NADPH binding site located in exon 6 (14). Reductase activity is associated only with the -18-variant (15), since the additional 6 amino acids probably disrupt the second $\beta$-sheet of the ferredoxin reductase $\beta \alpha \beta$-structure (14). The inactive variant (+18-variant) is less abundant, and constant ratios (100:1) have been reported for a variety of organs, such as fetal and adult adrenal as well as the testis. In tissues such as term placenta, fetal liver, kidney, lung, brain, muscle and heart, the +18 -form is barely detectable. An impact of chemotherapeutic drugs such as 5-FU on this ratio has not been reported, neither for cell lines nor for tissues. Therefore, we studied the impact of 5-FU on the splice variants of FDXR in normal intestinal and tumor tissue from 40 advanced colorectal cancer patients which had been treated with the 5-FU prodrug doxifluridine (5'DFUR).

\section{Materials and methods}

Forty patients $(\mathrm{n}=24$ males, $\mathrm{n}=16$ females; mean age 65 years, range 46-75 years) with advanced colorectal carcinoma but without serious complications were treated with 5'DFUR for 14 days, as described (16). Briefly, the administration of 5'DFUR (800-12,000 mg/day) was halted the day before surgery. The average dose administered to each patient was $1.3 \mathrm{~g}$ 5'DFUR. Two weeks after the curative surgery, treatment with 5'DFUR (600 mg/day) was restarted and continued for 2 years or for the remaining life span of the patient.

Tissue collection. Samples for histological diagnosis and RNA extraction were taken from tumor and the surrounding normal tissue of each patient prior to and after treatment. Specimens for RNA isolation were immersed immediately in Isogen (phenol/guanidine-isothiocyanate) and stored at $-80^{\circ} \mathrm{C}$ until RNA extraction.

RNA extraction and synthesis of $C D N A$ by reverse transcriptase polymerase chain reaction (RT-PCR). Total RNA was extracted (17), and the RNA content was quantified spectrophotometrically. The integrity of the RNA was judged by electrophoresis on $1.2 \%$ denaturing formaldehyde gels. The mixture $(50 \mu \mathrm{l})$ for the cDNA included $2 \mu \mathrm{g}$ total RNA, $3 \mu \mathrm{g} /$ $\mu 1$ random hexamers, 60 units ribonuclease inhibitor, $10 \mathrm{mM}$ dNTP mix, 0.1 M DTT, $250 \mathrm{mM}$ Tris- $\mathrm{HCl}$ and 100 units $\mathrm{Mu}-\mathrm{MLV}$ reverse transcriptase (Gibco, Rockville, MD, USA). Synthesis was performed at $37^{\circ} \mathrm{C}$ for $60 \mathrm{~min}$, and the cDNA was stored in aliquots at $-20^{\circ} \mathrm{C}$.

Quantitative real-time RT-PCR ( $q$-PCR). For quantitative realtime RT-PCR, analysis was performed using glass capillaries in the LightCycler ${ }^{\mathrm{TM}}$ instrument (Roche Diagnostics, Mannheim, Germany). The mRNA levels for the splice variants (FDXR-18, FDXR+18) and dihydropyrimidine dehydrogenase (DPD) were estimated by q-PCR. cDNA (diluted 1:10) $(5 \mu \mathrm{l})$, equivalent to $20 \mathrm{ng}$ of the initial RNA template, was used in each PCR. Two independent RT reactions were prepared for each RNA, and for each cDNA product, real-time PCRs were carried out in duplicate for a total of 4 readings. Each run included reaction mix controls with water in place of the template. As an additional negative control, quantifications of reactions prepared in parallel without addition of the RT enzyme were also run at least once for each set of replicate RT reactions. For quantification of each splice variant, cDNA (diluted 1:10) was amplified in a total volume of $10 \mu \mathrm{l}$ containing $3 \mathrm{mM} \mathrm{MgCl}_{2}$, specific 5' and $3^{\prime}$ oligonucleotide primers (FDXR-18: 12.5 pmol each, forward: 5'-GAA CGT GGC TCT GGA CGT, reverse 5'-TTC GTG ATG TCC GTT CT; FDXR+18: 25 pmol each, forward 5'-GAA CGT GGC TCT GGA CGT, reverse 5' TGT CCG TTC TCT GGC ACA A; DPD: 4 pmol each, forward 5'-CAG GAT CCA GAG CTG GTG CG, reverse 5'-TCT TGC GAT GCT CAC AAT ATC AGT GAC) synthesized by TIB MOLBIOL (Berlin, Germany) and $1 \mu \mathrm{l}$ LightCycler-FastStart DNA Master SYBR Green ${ }^{\circledR}$ I Kit, according to the manufacturer's instructions. To reduce sample-to-sample variability, results were calculated as ratios to DPD as a housekeeping gene.

PCR grade water was added to a total volume of $20 \mu \mathrm{l}$. The temperature profiles consisted of an initial denaturation step at $95^{\circ} \mathrm{C}$ (FDXR-18 for $10 \mathrm{~min}, \mathrm{FDXR}+18$ for $20 \mathrm{~min}$, DPD for $1 \mathrm{~min}$ ) followed by 40 amplification cycles [FDXR-18: denaturation at $95^{\circ} \mathrm{C}$ for $0 \mathrm{sec}$, annealing at $56^{\circ} \mathrm{C}$ for $5 \mathrm{sec}$, elongation at $72^{\circ} \mathrm{C}$ for $5 \mathrm{sec}$; FDXR+18: denaturation at $95^{\circ} \mathrm{C}$ for $10 \mathrm{sec}$, annealing at $64^{\circ} \mathrm{C}$ for $10 \mathrm{sec}$, elongation at $72^{\circ} \mathrm{C}$ for $10 \mathrm{sec}$; DPD: denaturation at $95^{\circ} \mathrm{C}$ for $0 \mathrm{sec}$, annealing at $58^{\circ} \mathrm{C}$ for $15 \mathrm{sec}$, elongation at $72^{\circ} \mathrm{C}$ for $15 \mathrm{sec}$. Ramp rates were set to $20^{\circ} \mathrm{C} / \mathrm{sec}$ (except DPD elongation at $3^{\circ} \mathrm{C} / \mathrm{sec}$ )]. Melting curves (FDXR: $95^{\circ} \mathrm{C}$ for $0 \mathrm{sec}, 45^{\circ} \mathrm{C}$ for $10 \mathrm{sec}, 95^{\circ} \mathrm{C}$ for $0 \mathrm{sec}$; DPD: $95^{\circ} \mathrm{C}$ for $0 \mathrm{sec}, 58^{\circ} \mathrm{C}$ for $30 \mathrm{sec}, 95^{\circ} \mathrm{C}$ for $0 \mathrm{sec}$ ) were analyzed to confirm the specificity (FDXR-18: $85.1^{\circ} \mathrm{C}$, FDXR+18: $86.2^{\circ} \mathrm{C}$, DPD: $67.6^{\circ} \mathrm{C}$ ) of the PCR amplification. External standards were used for the quantification of the unknown amounts. Standards were generated by PCR amplification from cDNA templates with the above-mentioned primers as follows. In a total volume of $50 \mu \mathrm{l}, 5 \mu \mathrm{l}$ cDNA, 10X PCR buffer containing $15 \mathrm{mM}$ $\mathrm{MgCl}_{2}, 4 \mu \mathrm{l} 150 \mu \mathrm{M}$ dNTPs, 40 pmol 5' and 3' oligonucleotides (each) and 1 unit Taq Gold Polymerase (Applied Biosystems, Weiterstadt, Germany) were mixed. The experimental protocol included $12 \mathrm{~min}$ of initial denaturation at $95^{\circ} \mathrm{C}$, followed by 35 amplification cycles at $95^{\circ} \mathrm{C}$ for $30 \mathrm{sec}, 65^{\circ} \mathrm{C}$ for $30 \mathrm{sec}$, $72^{\circ} \mathrm{C}$ for $30 \mathrm{sec}$ and a final period of a 3-min elongation. After amplification, the DNA fragments were purified with MicroSpin $^{\mathrm{TM}}$ S-300 HR columns (Amersham Biosciences, New York, NY, USA). The concentration of the respective DNA was determined by measuring absorbance in a spectral photometer at $260 \mathrm{~nm}$. Serial dilutions of the known DNA were used for standard curves. We tested the efficiency of the primers used for quantification of the splice variants with a second set of primers, and found that the primer pair of the +18 -variant was 3.72-fold more efficient, resulting in a correction factor of 0.27 . FDXR-18 and FDXR+18 mRNA levels were calculated as DPD ratios. Total FDXR was determined from the amounts of the splice variants.

Histological evaluation of treatment. Histological evaluation of the effect of 5'DFUR treatment was described by TanakaNozaki et al (16). Survival was determined at time of follow-up examination.

Statistical analysis. Significant differences between total FDXR, both splice variants and between subgroups were 
estimated by using the Student's t-test (SigmaPlot version 8.0). A significance level of $5 \%$ was established. Relations between total FDXR, -18-form and +18-form, the ratio -18/+18 and pathological effects were calculated by using correlation coefficients.

\section{Results}

Total FDXR mRNA levels and the distribution of the two alternative spliced variants in intestinal tissue. FDXR mRNA levels including the two splice variants were measured in normal intestinal tissue and tumor tissue of 40 cancer patients before and after 5'DFUR treatment using a sensitive and specific quantitative RT-PCR assay. Fig. 1 summarizes the results. Total FDXR mRNA levels (sum of variants) were 2-fold higher in tumor compared to normal tissue. This nearly statistically significant difference $(\mathrm{p}=0.051)$ was based on greater prominence of the -18-variant in tumor tissue (mean 2.29 $\times 10^{-3}$ ) compared to normal tissue surrounding the tumor $\left(1.15 \times 10^{-3}, \mathrm{p}=0.049\right)$. Similar to reported results from other tissue, the +18 -form was barely detectable in intestinal tissue. Nevertheless, we found similar trends for the invariant +18 -form, reaching 1.85-fold higher levels in tumors $(\mathrm{p}=0.053)$, while levels in non-treated tissues were almost equal to the detection limits. After 5'DFUR treatment, the levels for total FDXR mRNA were only slightly enhanced in normal tissue (1.64-fold, $\mathrm{p}=0.181$ ) while total levels in tumors were not significantly increased ( 1.13 -fold, $\mathrm{p}=0.638)$.

Earlier studies reported a constant 100:1 ratio in favor of the -18-variant for various tissues (9). Using our more sensitive technique, we evaluated this finding in tissue prior to treatment and found in normal tissue ( $\mathrm{n}=16$ cases) and additionally confirmed in tumor tissue ( $n=18$ cases) even higher ratios (up to 1000:1). After 5'DFUR treatment, the catalytic active -18-variant increased 1.28-fold in normal tissue and decreased slightly (0.94-fold) in tumors. The individual analysis clearly demonstrated that the variances were based on 8 individual cases $(n=37)$. In contrast, levels of the +18 -variant were clearly enhanced after 5'DFUR treatment; 31-fold in normal tissue $(p=0.019)$ and 17 -fold in tumor tissue $(p=0.071)$. Thus, 5'DFUR treatment for 14 days changed the ratio towards the +18 -variant (Fig. 1), reaching significant differences only in tumor tissue ( $\mathrm{p}=0.0118$ vs. $\mathrm{p}=0.0521$ for normal tissue). Thus, the proposed 100:1 ratio was now found only in 4 of 37 cases based on evaluation of normal tissue and in 6 of 38 cases based on tumor evaluation, while prior to treatment the -18- and +18 -variants differed significantly in normal $(\mathrm{p}=0.0356)$ and tumor $(\mathrm{p}=0.0006)$ tissue.

Association of the FDXR steady state mRNA level with treatment success and survival. FDXR enzyme activity sensitizes cells to ROS-induced apoptosis. Thus, we speculated from our results that induction of +18 mRNA splice variants might be associated with less successful treatment, based on the histological evaluation of the tissue sections or reduced survival time. Due to the small numbers in this study, only preliminary data could be gained but the predicted association $(r=-0.62)$ between +18 -variant mRNA induction and treatment in a subgroup of female patients was found. Furthermore, the increase in the +18 -variant in normal tissue was also associated

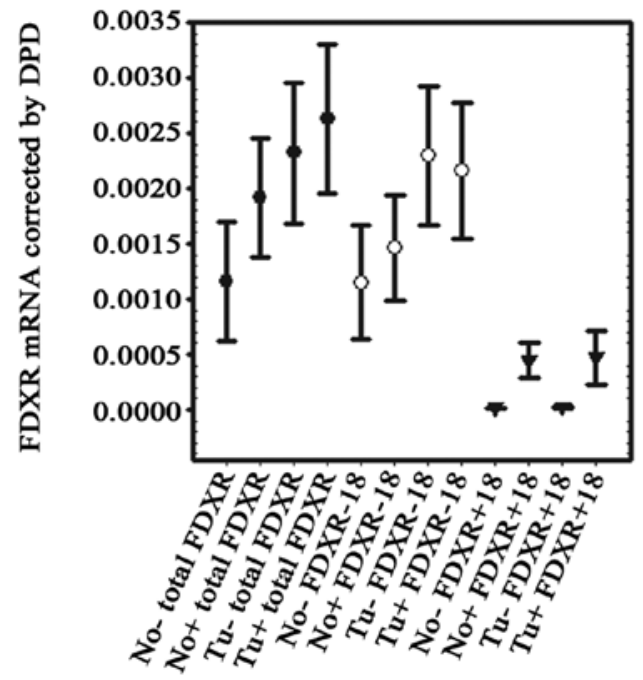

Tissue type before (-) and after (+) 5-FU treatment

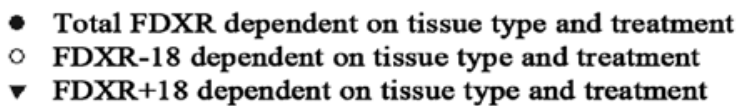

Figure 1. Total FDXR, FDXR-18 and FDXR+18 mRNA levels (mean \pm SE) in normal intestinal tissue (No) and tumor tissue (Tu) prior to (-) and after $(+)$ 5'DFUR treatment ( $\mathrm{n}=40$ cancer patients) estimated with sensitive and specific quantitative RT-PCR assay.

with no or limited treatment success (5 cases). Inversely, 8 of 14 successfully treated cases showed no or very limited induction in tumor tissue $(<1.3$-fold), while 4 of 5 patients with a strong induction of this variant had no or only minor treatment success.

\section{Discussion}

5-Fluorouracil (5-FU), one of the most useful antitumor agents (1), is well-known for its strong impact on different mRNAs (6). More recent in vitro data (7) indicate that p53-dependent apoptosis induced by 5 -FU treatment is mediated by ferredoxin reductase (FR). FR is located at the inner mitochondrial membrane and involved in an electron shuttle via ferredoxin, which is free in solution, to cytochrome P450 for the cholesterol sidechain cleavage. Electrons might leave this system and are transferred to other acceptors (18), thereby generating reactive oxygen species $\left(\mathrm{O}_{2}\right.$-radicals, $\left.\mathrm{H}_{2} \mathrm{O}_{2}\right)$ followed by induction of apoptosis. These data indicate that 5-FU induces overexpression of FDXR mediated by p53 or via a p53-independent manner which sensitizes tumor cells to ROS-induced apoptosis thereby overcoming apoptosis inhibition commonly found in tumors (19).

To extend this knowledge to in vivo circumstances, we estimated FDXR mRNA levels including the bioactive -18 splice-variant and the inactive +18 -variant in colorectal tissue of 40 patients prior to and after 5-FU (5'DFUR) treatment for 14 days. Treatment resulted in higher mRNA levels in tumor (1.13-fold) and normal tissue (1.64-fold), but these trends did not reach statistical significance. Hwang et al studied the impact of 5-FU on FDXR expression in the colorectal cancer cell line HCT 116 (7). They reported an 11-fold induction of 
total FDXR mRNA after 5-FU administration for $18 \mathrm{~h}$. We confirmed their findings and extended them to human tissue. Besides interindividual variations, also different time points, $18 \mathrm{~h}$ vs. 14 days in this report, may have accounted for the observed discrepancies. Comparing uninduced levels in tumor and normal tissue, we found that the level of the splice variants was approximately 2-fold higher in tumor than in normal tissue (FDXR-18: 2-fold, FDXR+18: 1.85-fold). Since FR is involved in the energy supply of cells, the observed higher level in tumor tissue may reflect a higher demand for FDXR enzyme activities of tumors, either based on increased transcription and/or stabilized mRNA in tumor tissue.

Looking at the ratios between the splice variants, we observed an overrepresentation of ratios between 10:1 and 1000:1 in contrast to the published fixed relation of 100:1 in favor of the -18-variant. We speculate that these differences could be based on the different methods used. Our wide range is most likely a result of the very sensitive assay (quantitative RT-PCR) used in this study. On the other hand, we cannot formally rule out that levels may be different in intestinal tissue since no results have been published to date for this tissue and tumor tissue of cancer patients. Indeed, we found an even more unbalanced ratio in tumor tissue, although it was reported that they are generated by a non-regulated mechanism (9). After treatment, the functional -18-variant was slightly underrepresented in the tumors (0.94-fold), and somewhat increased values were found in normal tissue (1.28-fold). In contrast, the level of the inactive splice variant (+18-variant) increased drastically in tumor (17-fold) and normal tissue (31-fold). Overall, constant predominance of the -18-variant $(100: 1)$ was only found in 4 normal tissues $(n=37)$ and in 6 tumors $(n=38)$. Thus, the $-18 /+18$ ratio shifted extremely to the +18 -variant. Some cases showed even a predominance of the +18 -variant after treatment. This was found in normal $(n=10)$ and tumor tissue $(n=2)$. We explored several explanations for these results. Although not reported for the splice process of FDXR, differential regulation of splicing may account for our findings. Then, 5-FU interfered with the splicing process causing the observed increase in the +18 -variant. On the other hand, the results could have been due to the increased stability of the +18 -variant. It has previously been reported that binding elements in introns or alternative splicing at the beginning of an exon such as in FDXR pre-mRNA may change the stability of the +18 mRNA. In this context, the induced apoptosis and cell death actively reduce levels of the FDXR-18 mRNA (20).

Tothis end, we speculated that induction of the nonfunctional +18 -variant might be associated with nonsuccessful treatment. We found that high +18 -variant levels were inversely associated with successful treatment based on histological evaluation of specimens $(\mathrm{r}=-0.62)$; while no or a minor induction $(<1.3)$ was associated with successful treatment (8 of 14 patients). From these results, it can be speculated that the association of the +18 -form with ineffective treatment may depend on the inability to generate oxidative stress. The alternative splicing at the end of exon 7 directly adjacent to the NADPH-binding site of FR would probably disrupt the second $\beta$-sheet of the ferredoxin reductase $\beta \alpha \beta$-structure of the NADPH-binding site (8). Consequently, binding of NADPH and the substrate hydroxylation and otherwise an induction of apoptosis via the leak of electrons for generation of $\mathrm{O}_{2}$ radicals (18) would not be possible for the +18 -form. In addition, it has been shown that the +18 -form did not exhibit reductase activity (15). Further efforts may clarify whether the +18 -form is really unable to produce oxidative stress and to induce apoptosis and may also elucidate the process of 5-FU-induced +18-variant expression.

\section{References}

1. Heidelberger C, Chaudhuri NK, Danneberg P, et al: Fluorinated pyrimidines, a new class of tumour-inhibitory compounds. Nature 179: 663-666, 1957.

2. Kelder W, Hospers GA and Plukker JT: Effects of 5-fluorouracil adjuvant treatment of colon cancer. Expert Rev Anticancer Ther 6: 785-794, 2006

3. Navolanic PM and McCubrey JA: Pharmacological breast cancer therapy (Review). Int J Oncol 27: 1341-1344, 2005.

4. Patt YZ, Hassan MM, Lozano RD, Brown TD, Vauthey JN, Curley SA and Ellis LM: Phase II trial of systemic continuous fluorouracil and subcutaneous recombinant interferon alpha- $2 \mathrm{~b}$ for treatment of hepatocellular carcinoma. J Clin Oncol 21: 421-427, 2003.

5. Santi DV, McHenry CS and Sommer H: Mechanism of interaction of thymidylate synthetase with 5-fluorodeoxyuridylate. Biochemistry 13: 471-481, 1974.

6. Parker WB and Cheng YC: Metabolism and mechanism of action of 5-fluorouracil. Pharmacol Ther 48: 381-395, 1990.

7. Hwang PM, Bunz F, Yu J, et al: Ferredoxin reductase affects p53dependent, 5-fluorouracil-induced apoptosis in colorectal cancer cells. Nat Med 7: 1111-1117, 2001.

8. Liu G and Chen X: The ferredoxin reductase gene is regulated by the p53 family and sensitizes cells to oxidative stress-induced apoptosis. Oncogene 21: 7195-7204, 2002.

9. Brentano ST, Black SM, Lin D and Miller WL: cAMP post-transcriptionally diminishes the abundance of adrenodoxin reductase mRNA. Proc Natl Acad Sci USA 89: 4099-4103, 1992.

10. Miller WL: Molecular biology of steroid hormone synthesis. Endocr Rev 9: 295-318, 1988.

11. Jefcoate CR, McNamara BC and DiBartolomeis MJ: Control of steroid synthesis in adrenal fasciculata cells. Endocr Res 12: 315-350, 1986.

12. Solish SB, Picado-Leonard J, Morel Y, Kuhn RW, Mohandas TK, Hanukoglu I and Miller WL: Human adrenodoxin reductase: two mRNAs encoded by a single gene on chromosome 17cen----q25 are expressed in steroidogenic tissues. Proc Natl Acad Sci USA 85: 7104-7108, 1988.

13. Chandra J, Samali A and Orrenius S: Triggering and modulation of apoptosis by oxidative stress. Free Radic Biol Med 29: 323-333, 2000.

14. Lin D, Shi YF and Miller WL: Cloning and sequence of the human adrenodoxin reductase gene. Proc Natl Acad Sci USA 87: 8516-8520, 1990.

15. Brandt ME and Vickery LE: Expression and characterization of human mitochondrial ferredoxin reductase in Escherichia coli. Arch Biochem Biophys 294: 735-740, 1992.

16. Tanaka-Nozaki M, Tajiri T, Tanaka N, et al: Intratumoral induction of thymidylate synthase mRNA by 5-FU in colorectal cancer patients: association with survival. Oncol Rep 10: 1425-1429, 2003.

17. Chomczynski $\mathrm{P}$ and Sacchi N: Single-step method of RNA isolation by acid guanidinium thiocyanate-phenol-chloroform extraction. Anal Biochem 162: 156-159, 1987.

18. Hanukoglu I, Rapoport R, Weiner L and Sklan D: Electron leakage from the mitochondrial NADPH-adrenodoxin reductaseadrenodoxin-P450scc (cholesterol side chain cleavage) system. Arch Biochem Biophys 305: 489-498, 1993.

19. Bedi A, Pasricha PJ, Akhtar AJ, et al: Inhibition of apoptosis during development of colorectal cancer. Cancer Res 55: 1811-1816, 1995.

20. Nott A, Meislin SH and Moore MJ: A quantitative analysis of intron effects on mammalian gene expression. RNA 9: 607-617, 2003. 